\title{
Ventricular septal defect and aortic regurgitation
}

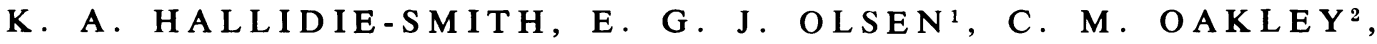 \\ J. F. GOODWIN, AND W. P. CLELAND \\ From the Unit of Clinical Cardiology, the Unit of Cardiothoracic Surgery, and the \\ Department of Morbid Anatomy, Royal Postgraduate Medical School, London W.12
}

\begin{abstract}
We have reviewed our experience of 29 patients with the association of ventricular septal defect and aortic regurgitation, 27 of whom have been treated surgically. Our present approach to the surgical management is outlined and the embryology and pathological anatomy are reviewed. The most common cause of aortic regurgitation was a prolapsed aortic valve cusp, which occurred in 19 patients. Aneurysmal dilatation of an aortic sinus accounted for the regurgitation in three patients, and two patients had both abnormalities. In two patients no cause for the aortic regurgitation was found. Those patients with aortic cusp prolapse commonly had large ventricular septal defects, of which nearly a third were supracristal. Because of cusp prolapse into the ventricular septal defect, and sometimes into the right ventricular outflow tract, the findings at cardiac catheterization often suggested erroneously that the ventricular septal defect was small and that infundibular obstruction was present. Characteristic angiographic features have been demonstrated, in particular the deformed and prolapsed aortic cusp. The various techniques of surgical correction which were used are described, the majority of patients having had a patch closure of the ventricular septal defect and repair of the aortic valve. Some residual aortic regurgitation was usual, but it was improved or minimized in 18 of the 23 survivors, and the more recent results have been particularly encouraging. Closure of the ventricular septal defect alone relieved heart failure in a 3 -year-old child. There were four operative deaths $(15 \%$ mortality) in patients with severe aortic regurgitation, three of whom were in heart failure before operation. The medical course was commonly of slowly increasing severity of the aortic regurgitation with progression to heart failure. However, the individual course was unpredictable and three children developed heart failure within a year of the onset of their aortic regurgitation. Infective endocarditis occurred in a quarter of the patients and usually followed the development of the aortic regurgitation. Despite the difficulties of surgical management it is felt that the unpredictable prognosis, high operative risk once cardiac failure has supervened, and the hazard of infective endocarditis make early operation desirable.
\end{abstract}

The association of ventricular septal defect and aortic regurgitation was first described by Laubry and Pezzi in 1921. Since then, although only approximately 150 cases have been reported in the literature, the development of aortic regurgitation has come to be recognized as one of the more common and the most serious of the complications of ventricular septal defect.

This combination of defects has a poor medical prognosis, and so with improving surgical techniques total correction is being more widely advocated. Surgical correction is not always easy, and success depends largely on a comprehensive knowledge of the anatomy and function of the aortic valve.

IOn a grant from the British Heart Foundation

sSupported by the British Heart Foundation

\section{THE PATIENTS STUDIED}

Between 1958 and 1967 we investigated 29 patients with ventricular septal defect and aortic regurgitation, 27 of whom had been surgically corrected. This is the largest series so far reported. This group represents $12 \%$ of our series of 229 surgically treated ventricular septal defects. Since the majority of the patients are specially referred this figure may give a falsely high percentage of incidence.

Our patients consisted of 17 males and 12 females, between 2 and 37 years of age at the time of investigation, and 3 and 38 years at the time of operation, when 15 patients were less than 16 years. 
HISTORY The early history of the adult patients was difficult to elicit. Nine of the 15 children gave a history of failure to thrive in infancy; 13 of the total number of patients complained of some limitation of effort tolerance, and six developed signs of heart failure.

In 20 of the 29 patients a heart murmur was heard in early infancy, and in a further eight it was first noted between the ages of 3 and 8 years, usually at a school medical examination. The remaining patient, a West Indian, was never examined in childhood.

The initial murmur was known to have been solely systolic in 19 patients. The time of appearance of the diastolic murmur was well documented in 11 children, and varied between 2 and 12 years. In eight other children the exact time of appearance of the diastolic murmur was uncertain, but all of them were between 2 and 13 years when it was first noted. The remaining patients presented in adult life with an established diastolic murmur.

Seven of our patients (24\%) provided a clear history of subacute infective endocarditis, but in none was it certain that the infection preceded the aortic regurgitation. The aortic regurgitation, however, preceded the subacute infective endocarditis in three patients.

PHYSICAL SIGNS Nine of the 15 children were undersized, particularly in regard to weight. Bulging of the chest, particularly of the left side, was common.

In all patients the pulses were described as jerky or ill-sustained. In 17 patients the diastolic arterial blood pressure was below $40 \mathrm{~mm}$. $\mathrm{Hg}$, and in 15 patients the arterial pulse pressure was $60 \mathrm{~mm}$. or more.

A left ventricular impulse was noted in all the patients, and some degree of right ventricular hypertrophy in 14. A systolic thrill at the left sternal edge was common. Both the systolic and diastolic murmurs were commonly described as maximal at the lower left sternal edge, but the pulmonary area was thought to be the site of maximum intensity in a few. Three patients with right ventricular infundibular stenosis had loud systolic murmurs in the pulmonary area.

The murmurs were variously described, the description varying not only between different observers but between different examinations by the same observer.

Most often it was thought that the systolic murmur filled systole, stopping at the second sound and followed by a decrescendo early dia- stolic murmur. Sometimes the murmurs were thought to be truly continuous, the diastolic murmur following the systolic murmur without intermission. The majority of patients had a third heart sound and a short apical mid-diastolic murmur.

The aortic regurgitation was assessed as mild in 5 , moderate in 13 , and severe in 11 on the basis of the clinical findings, electrocardiogram, and chest radiograph.

The most difficult differential diagnosis of ventricular septal defect with aortic regurgitation was from a sinus of Valsalva fistula into the right ventricle. Other differential diagnoses considered in some patients, particularly early in our experience, were patent ductus arteriosus, aortopulmonary window, coronary artery fistula, and isolated aortic valve disease. Three patients had had a previous thoracotomy elsewhere for a supposed patent ductus arteriosus.

PHONOCARDIOGRAPHY Recordings were carried out in all the patients. They confirmed that the most common murmurs were as described clinically but illustrated the similarity of the murmurs in some patients to those found in sinus of Valsalva fistula, patent ductus arteriosus, and aortic valve disease (Fig. 1). The second sound was widely split in the presence of infundibular pulmonary stenosis.

ELECTROCARDIOGRAPHY All the records showed some evidence of left ventricular hypertrophy, ranging from slight in 12 to severe in five. There was unequivocal evidence of biventricular hypertrophy in the three children who had infundibular pulmonary stenosis requiring resection. Two patients had incomplete right bundle-branch block while three, all with severe aortic regurgitation, showed evidence of left atrial hypertrophy. The frontal plane axis varied from $+30^{\circ}$ to $+70^{\circ}$ in all but two patients, who had left axis deviation of $-30^{\circ}$ and $-40^{\circ}$ respectively, which was unrelated to the severity of the aortic regurgitation or to the site or size of the ventricular septa defect. Several patients showed progressive left ventricular hypertrophy, coinciding with progression of the aortic regurgitation (Fig. 2).

RADIOGRAPHY There was some left ventricular enlargement in all patients, and the cardiothoracic ratio was over $50 \%$ in all save two. Right-sided enlargement was noted in 16 patients, including the six in heart failure and three with a systolic right ventricular outflow tract gradient of over $50 \mathrm{~mm}$. Hg. Ten patients showed some left atrial 

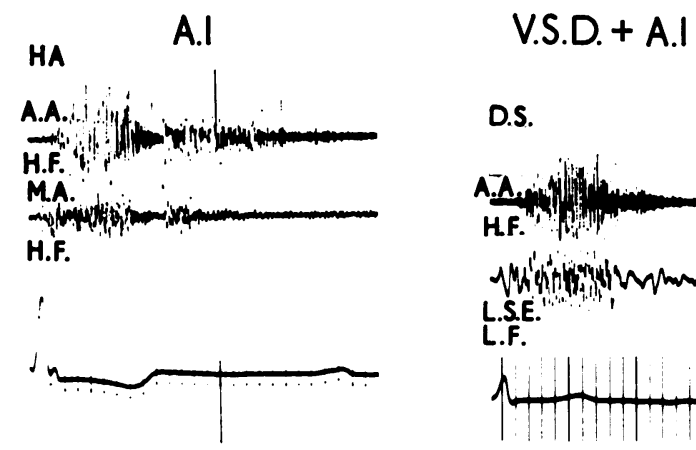

D.S.

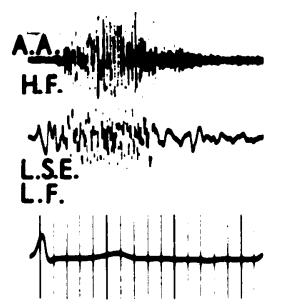

Sinus of valsalva defect
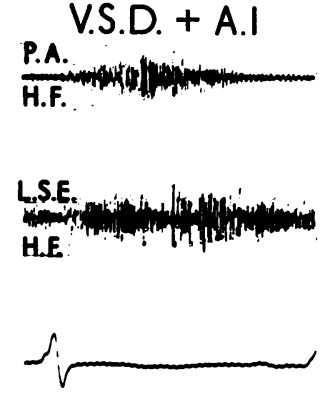
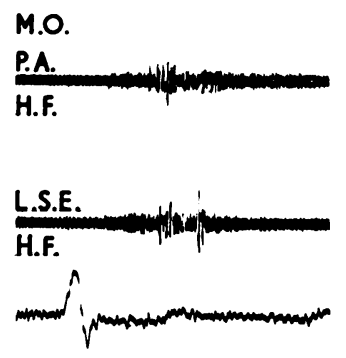

Z.B.

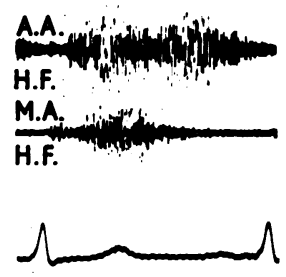

P.D.A.

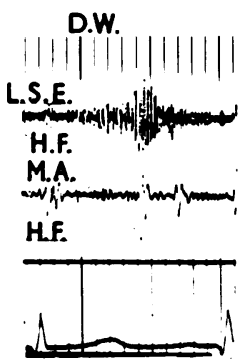

FIG. 1. Phonocardiograms of three patients with ventricular septal defect and aortic regurgitation compared with those of rheumatic aortic regurgitation, sinus of Valsalva fistula from aorta to right ventricle, and patent ductus arteriosus respectively. $A .1=$ aortic regurgitation; $V . S . D .=$ ventricular septal defect; P.D.A. = patent ductus arteriosus; $P . A .=$ pulmonary area; $A . A .=$ aortic area; H.F. = high frequency; L.S.E. = left sternal edge; M.A.=mitral area.

enlargement, while right atrial enlargement was noted in the patients in heart failure. The main pulmonary artery was often prominent. The lung fields were assessed as slight or moderately overfilled in all but five patients. Serial increase in heart size correlated with the speed of progression of the aortic regurgitation (Fig. 3a, b). The degree of left ventricular enlargement sometimes appeared disproportionately great in regard to the severity of the aortic regurgitation. This could be accounted for by the additional volume load on the left ventricle imposed by the presence of the ventricular septal defect.

CARDIAC CATHETERIZATION Right heart catheterization was carried out in all the patients (Table).

There were certain characteristics of the group as a whole (Figs 4 and 5). A systolic pressure gradient below the pulmonary valve or high in the body of the right ventricle was common, and was $20 \mathrm{~mm}$. $\mathrm{Hg}$ or more in 12 patients. Three of these patients had infundibular hypertrophy requiring resection, but in the remaining nine the gradient was abolished after correction of the ventricular septal defect and aortic regurgitation, without infundibular resection.

Despite the fact that most of the ventricular septal defects were of a size that an elevated pulmonary artery pressure or one balanced with the systemic arterial pressure would be expected, in fact there was only one patient in whom the pulmonary artery pressure was more than moderately elevated. This patient was the only one who had a raised pulmonary vascular resistance (10 units). The other patients had normal or slight to moderate elevation of the pulmonary artery pressure and normal pulmonary vascular resistances.

The majority of patients had small left-to-right shunts with a ratio of pulmonary to systemic flow of less than 2:1. However, six patients with a pulmonary artery systolic pressure of $40 \mathrm{~mm}$. or less had large left-to-right shunts with a ratio of pulmonary to systemic flow of around $3: 1$. The left atrial mean pressure was normal except in those patients in heart failure, in whom it was elevated to between 15 and $20 \mathrm{~mm}$. $\mathrm{Hg}$. The 

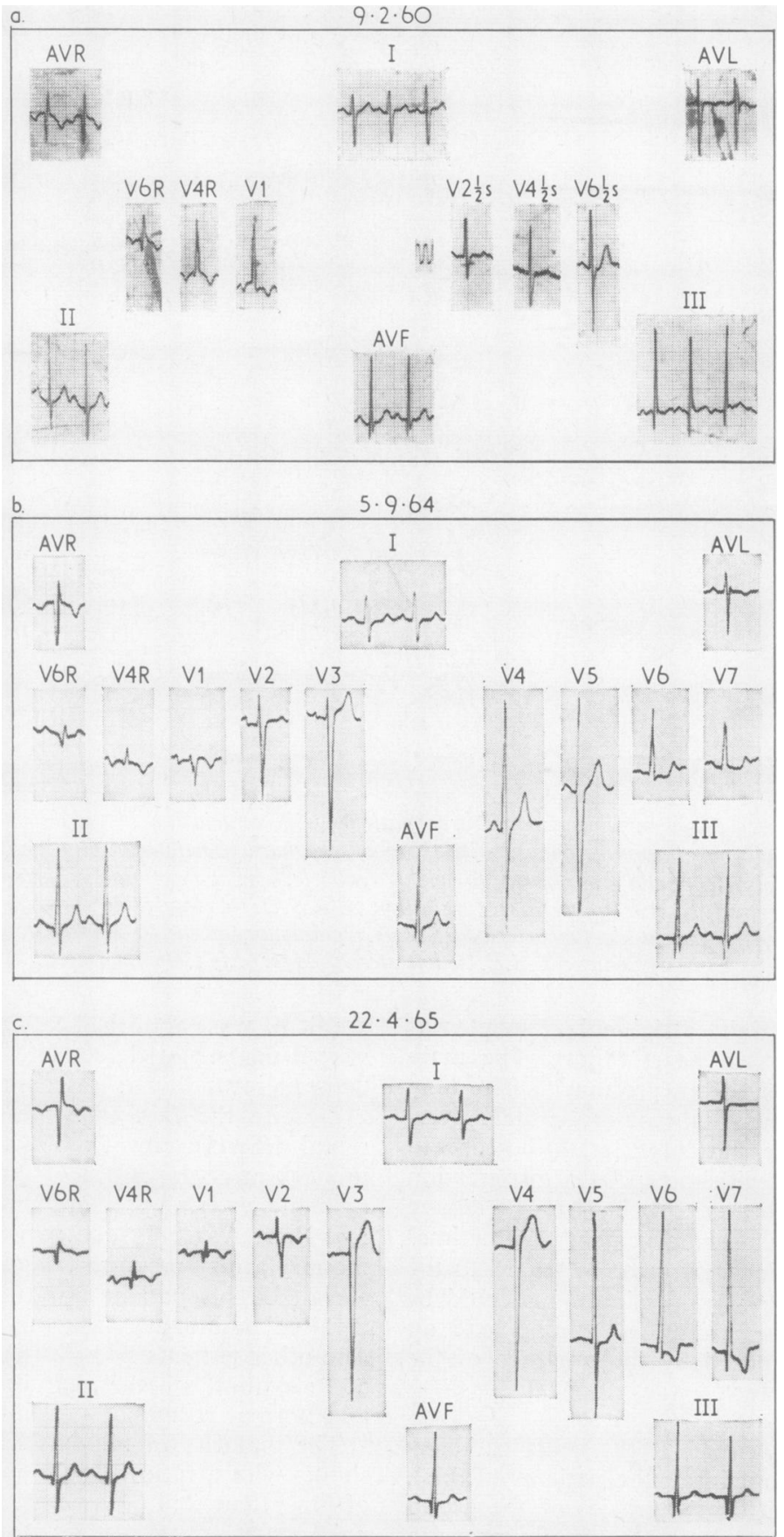

FIG. 2. Case 14. Serial electrocardiograms (a) at age 11 months with physical signs of a large septal ventricular defect, showing right ventricular hypertrophy; (b) two months after onset of aortic regurgitation, at age 5 years, showing left ventricular hypertrophy developing; (c) seven months later, demonstrating rapidly progressive left ventricular hypertrophy. 
(b)

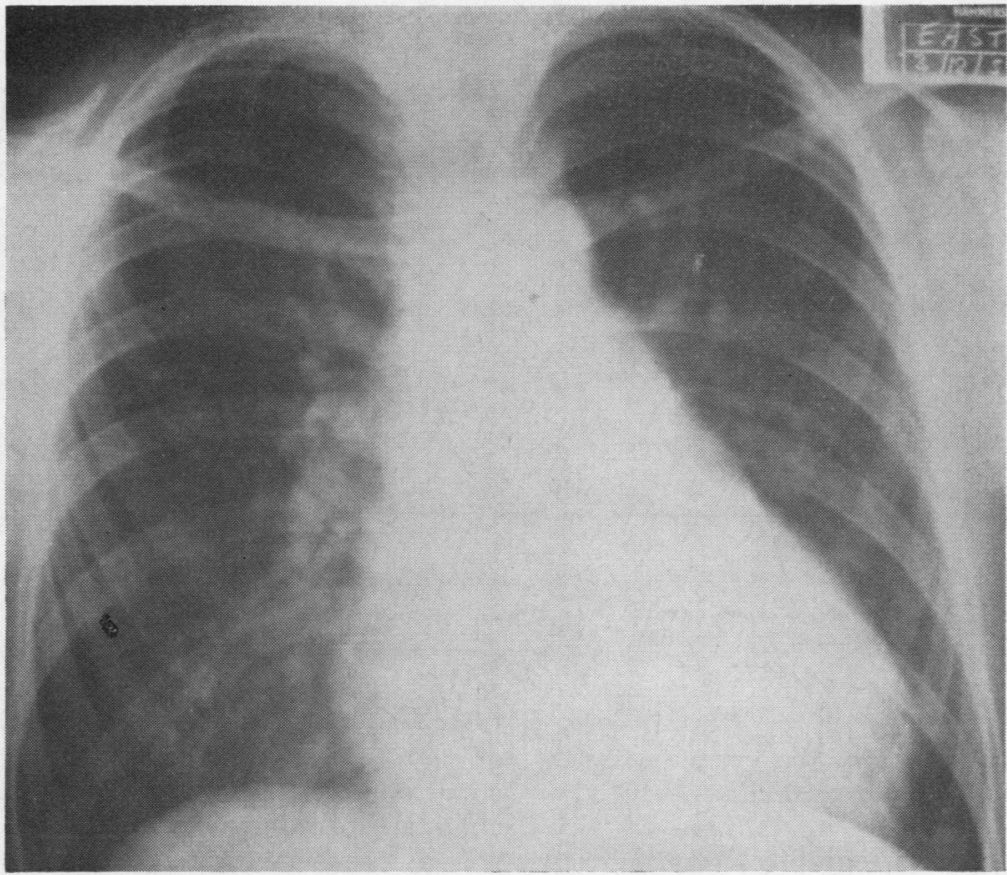

FIG. 3. Case 5. Postero-anterior chest radiographs (a) several months after the development of aortic regurgitation; (b) 15 months later, demonstrating increasing left ventricular enlargement. 
FIG. 4. Ratio of pulmonary to systemic flow (P/S flow ratio) plotted against pulmonary artery pressure (left) and right ventricular pressure (right). $R V=$ right ventricle; $P A=$ pulmonary artery.

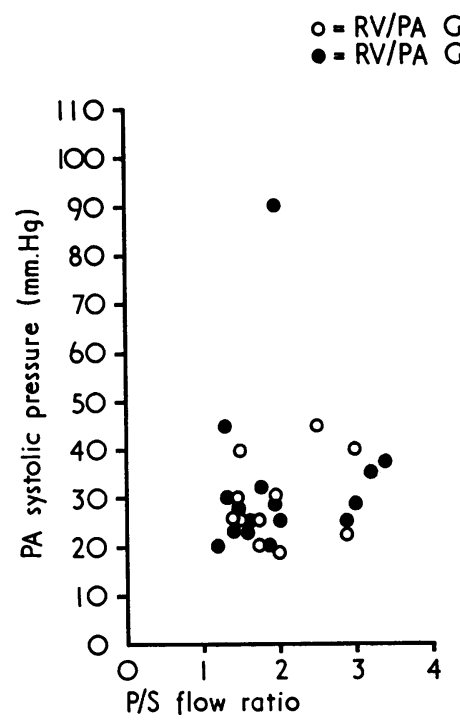

$0=R V / P A$ Gradient over $20 \mathrm{~mm}$.

$\bullet=R V / P A$ Gradient $0-20 \mathrm{~mm}$.
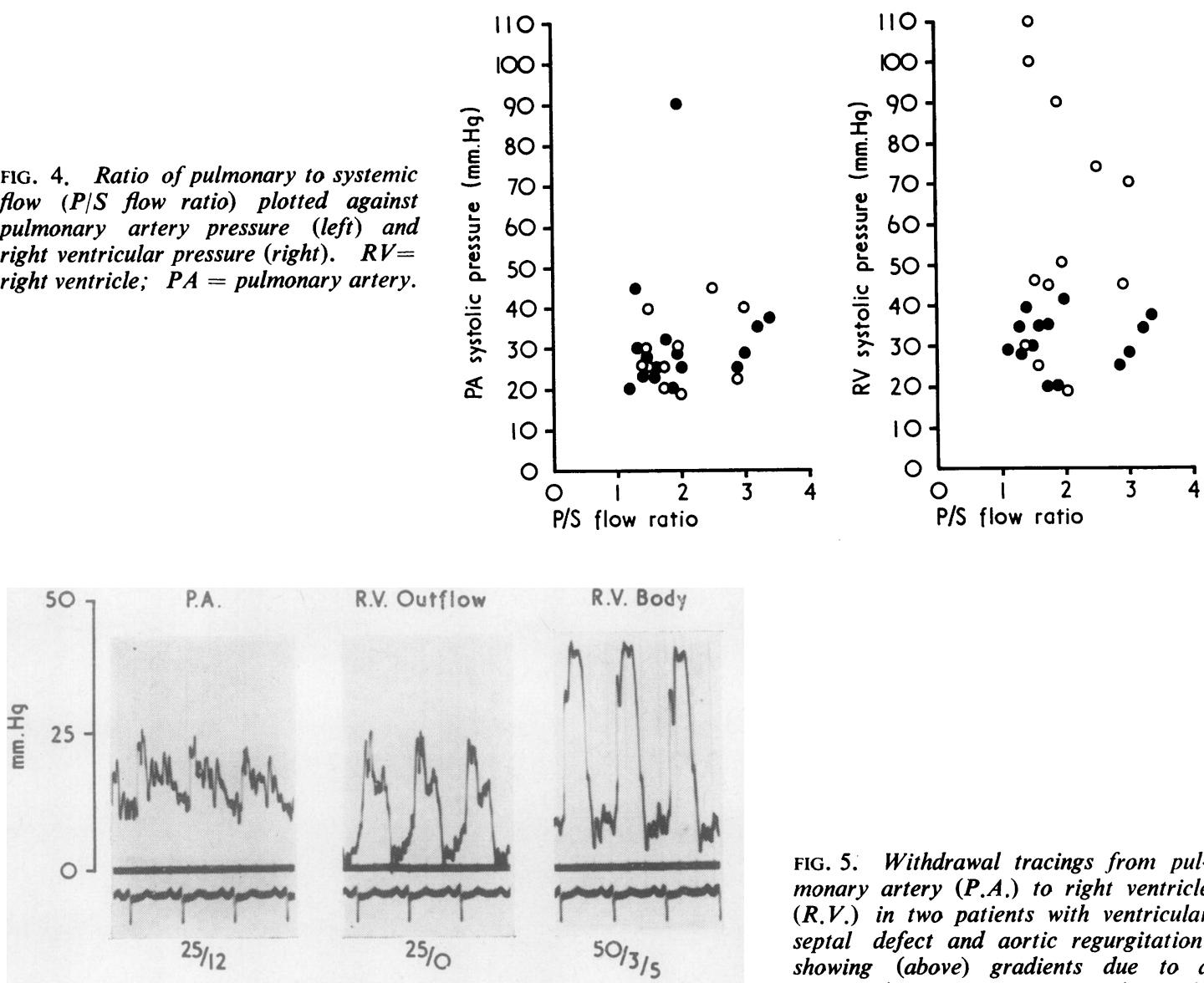

R.V. Body

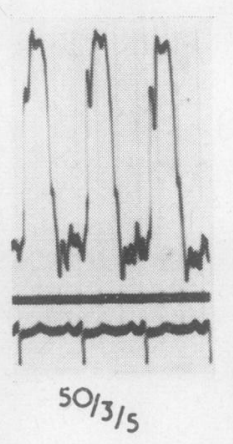

FIG. 5. Withdrawal tracings from pulmonary artery (P.A.) to right ventricle $(R . V$.$) in two patients with ventricular$ septal defect and aortic regurgitation, showing (above) gradients due to a prolapsed cusp obstructing the right ventricular outflow tract, and (below) infundibular stenosis.

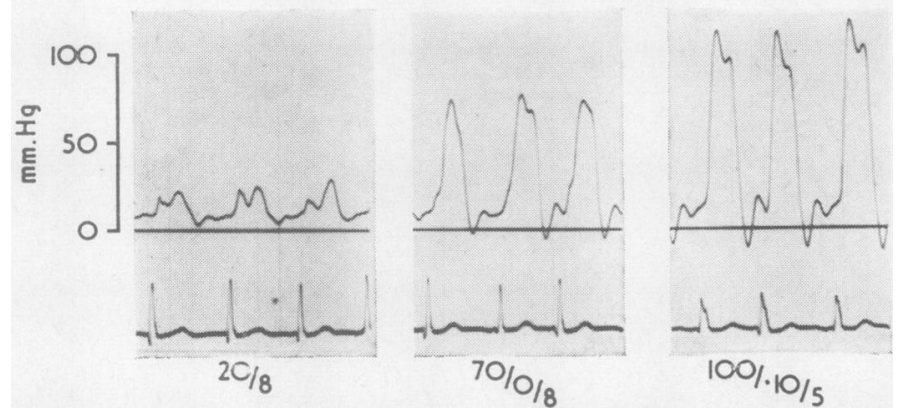

haemodynamic findings could be correlated with the angiographic and operative findings.

ANGIOCARDIOGRAPHY Aortography was carried out in 24 patients by the retrograde Seldinger technique (Seldinger, 1953), using cine angio- graphy in 13. Six of these patients had left ventricular angiocardiograms and four had right ventricular angiocardiograms. The aortic regurgitation was assessed as severe in nine, moderate in 10 , slight in four, and trivial in one, agreeing well with the clinical grading. 
The left ventricle was assessed as enlarged in all except two, and there was dilatation of the ascending aorta in all with marked systolic expansion. There was right ventricular enlargement in those patients in heart failure or with a significant right ventricular outflow tract pressure gradient.

Characteristically (Fig. 6a-c) there was a systolic shunt from the left ventricle to the right ventricle through the ventricular septal defect or directly from the aorta to the right ventricle through a sinus of Valsalva fistula, with early opacification of the right ventricular outflow tract. In diastole the regurgitant jet of contrast from the aorta split up, one stream going directly to fill the left ventricle and the other passing to the right ventricle through the ventricular septal defect or directly through a sinus of Valsalva fistula.

A prolapsed aortic valve cusp, usually the right

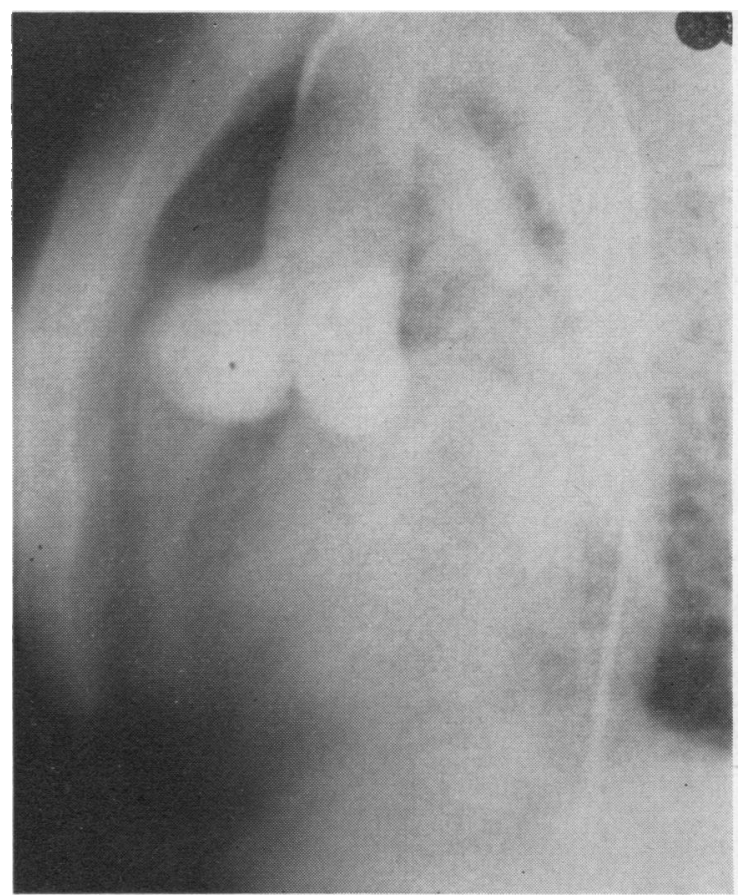

(b)

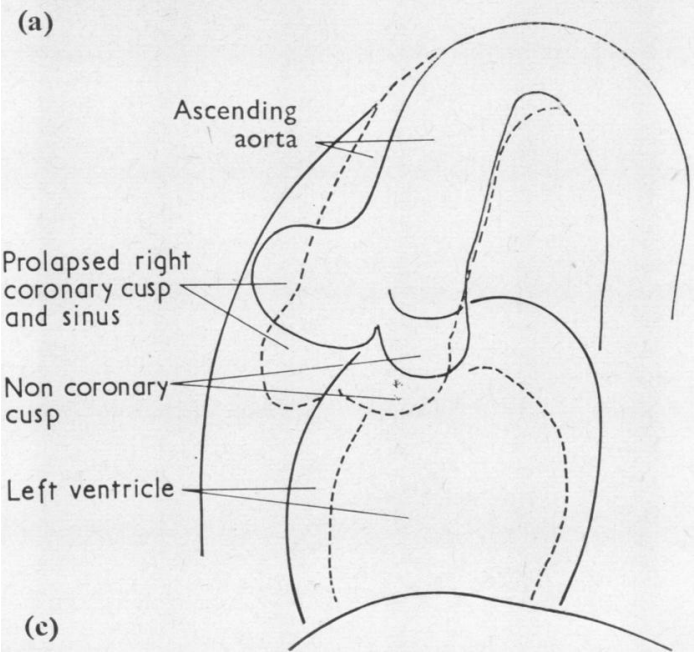




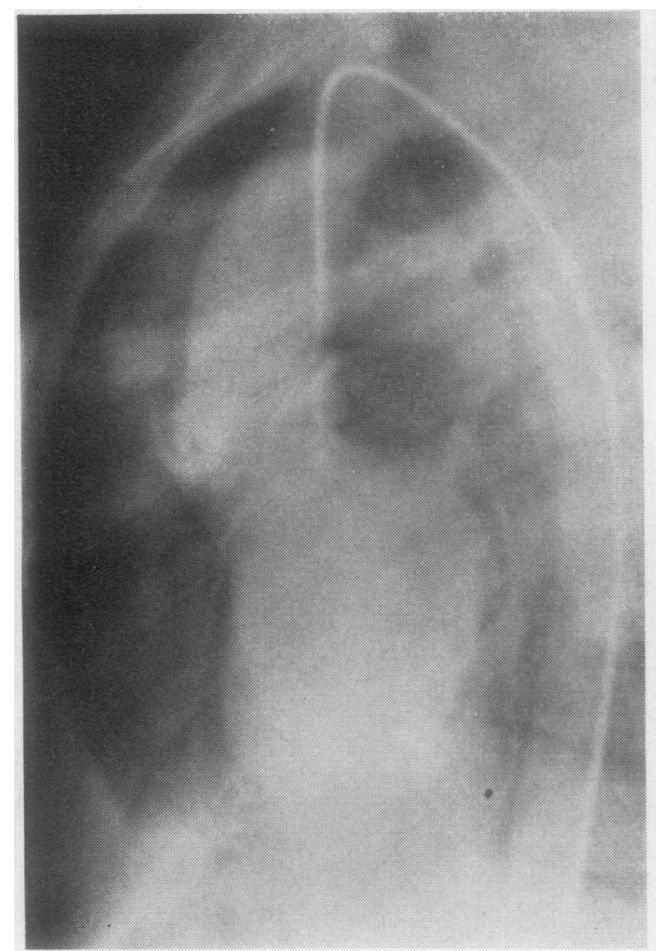

(a)

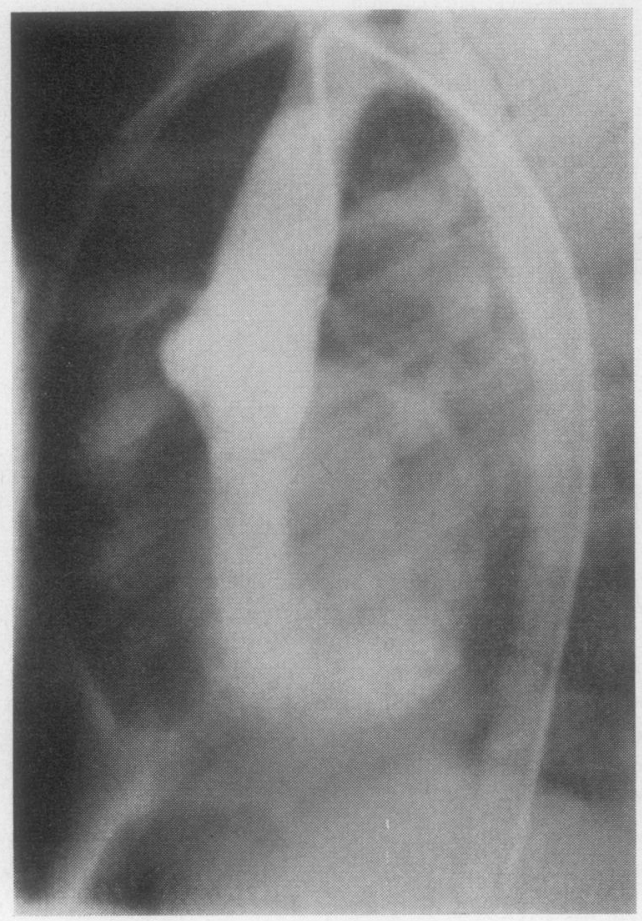

(c)

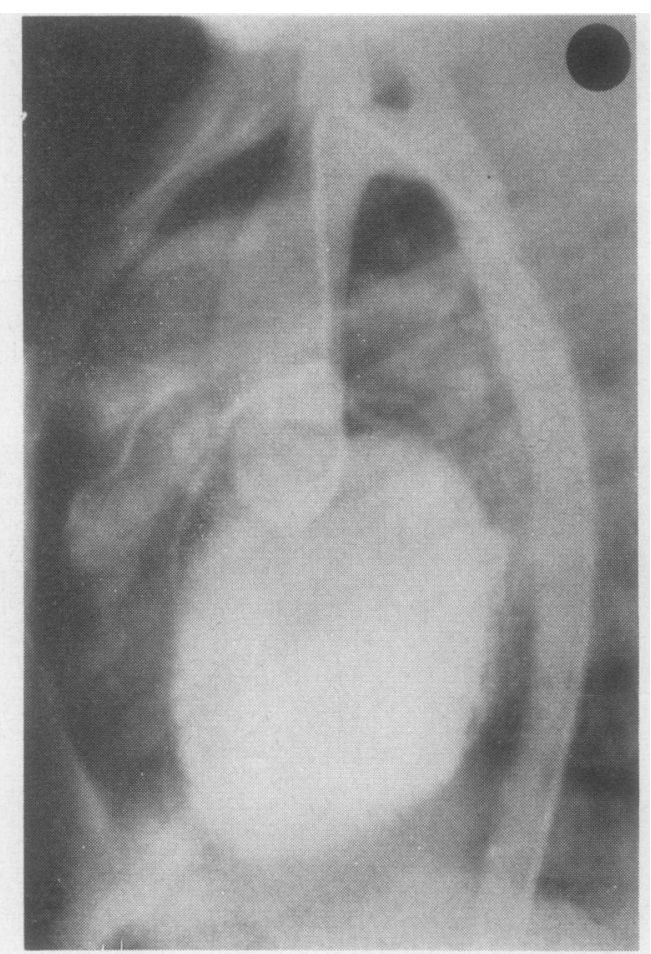

(b)

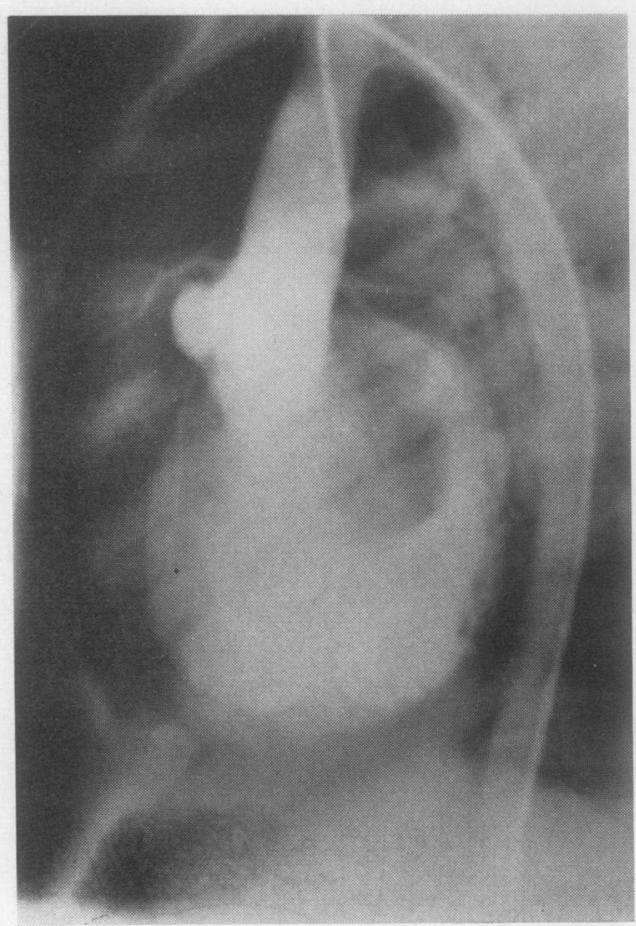

(d) 
coronary, which was the cause of the aortic regurgitation in the majority of our patients, gave certain characteristic appearances (Figs 6 and 7). In diastole there was a berry-shaped or 'squared off' appearance to the affected cusp and sinus. In systole the cusp appeared more deformed and tended to retain contrast medium. The redundant cusp often showed a double contour, and the deformed cusp and sinus could be seen bulging into the right ventricular outflow tract. An exaggeration of normal aortic root movement was noted (Fig. 6).

Aortograms of the patients with sinus of Valsalva aneurysms and fistulae showed the affected sinus to be dilated both in systole and diastole (Fig. 8) with no obvious abnormality of the aortic valve cusps.

In the absence of a deformed cusp, it was not always possible to distinguish by angiocardiography between a sinus of Valsalva fistula into the right ventricle and a ventricular septal defect (particularly a supracristal one) with aortic regurgitation due to an incompetent valve. It is possible that left ventricular cine angiocardiography with careful differentiation between systolic and diastolic shunts could help to elucidate this further.

SURGICAL MANAGEMENT The type of surgical management is largely dictated by the severity of the aortic regurgitation. If the latter is minimal it is unlikely that any special measures will be required, either to handle the perfusion or to deal with the aortic valve. In earlier patients it was hoped that repair of the ventricular septal defect would lead to a reduction or even abolition of the aortic leak, but these hopes were ill-founded. However, with few exceptions further progress of the aortic regurgitation has been halted. Possibly, however, closure of the ventricular septal defect alone may reduce the risk of infection.

In patients with moderate or severe aortic regurgitation, aortic cross-clamping will be required if an adequate body perfusion is to be carried out and if the operative field is to be kept relatively dry. In these patients the aorta should be opened in order that the valve can be carefully inspected both from above and from below, and

FIG. 7. Lateral aortogram of a 3-year-old child with ventricular septal defect and prolapsed right coronary cusp, demonstrating particularly well the deformed cusp and sinus. (a) early systole; (b) late diastole; (c) early diastole; (d) late diastole.

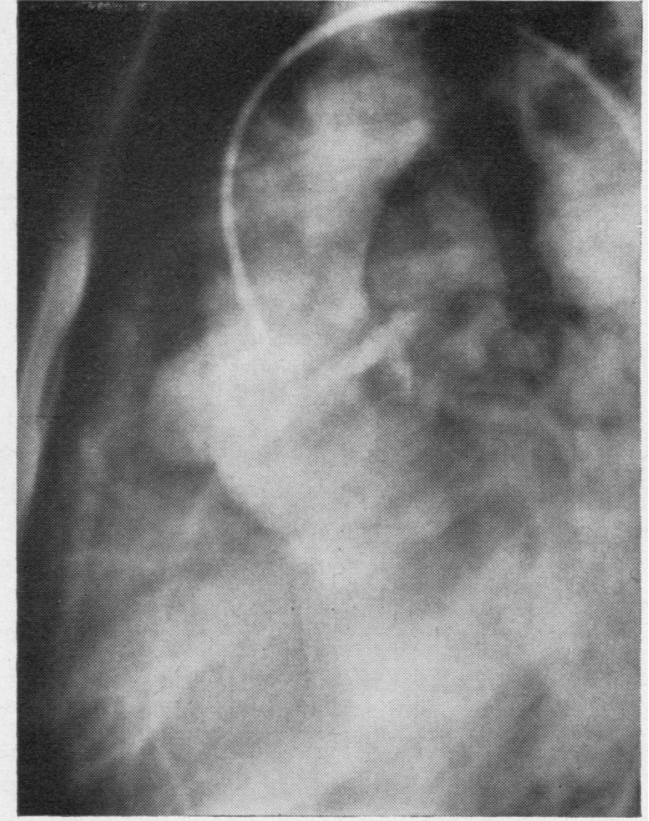

(a)

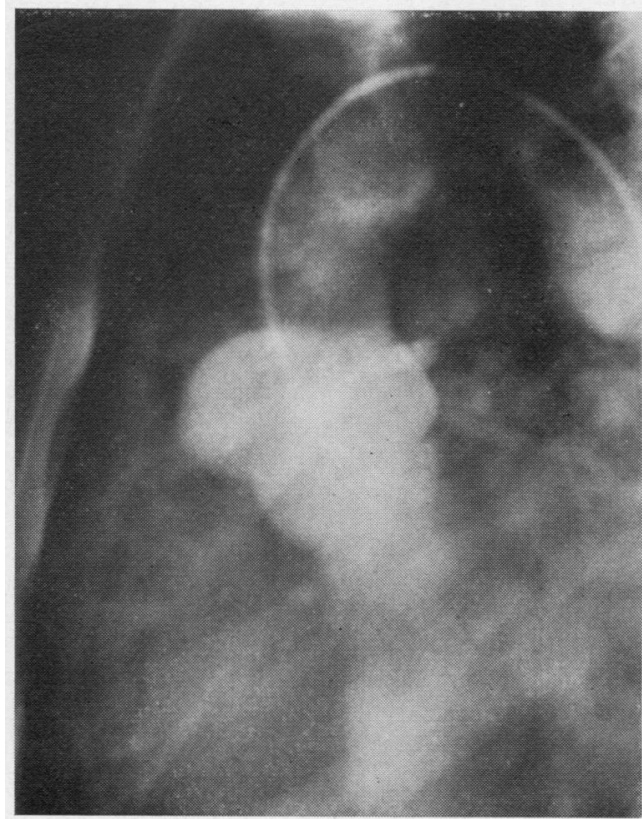

(b)

FIG. 8. Lateral aortograms of a patient with sinus of Valsalva fistula from right aortic sinus to right ventricle to show characteristic deformity of sinus $(a)$ in systole and $(b)$ in diastole, aortic regurgitation, and opacification of the right ventricle. 
so that the coronary vessels can be cannulated and perfused.

The valve should be very carefully inspected in order to determine the exact cause of regurgitation. Some valves are capable of reconstruction or repair, whereas others are so grossly deformed that replacement with a homograft or a mechanical prosthesis is required.

The following techniques have been used in the patients recorded here:

(a) Simple repair of a ruptured sinus of Valsalva or perforated cusp: in these patients the cusps themselves are reasonably normal, and meet centrally so that reinforced sutures of the perforation result in a competent valve.

Sometimes the aortic annulus is dilated as a result of the regurgitation, so that the cusps do not meet centrally. In such cases the cusps may be widened by suturing a strip of fascia lata to their free edges or the valve may require replacement.

(b) The commonest abnormality is the prolapsed and grossly redundant right coronary cusp, often associated with enlargement of the relevant sinus of Valsalva. In such cases it is often difficult to determine the precise position of the aortic annulus into which the stitches for closing the ventricular septal defect should be inserted. An attempt should be made to correct the regurgitation by shortening the cusp and elevating it slightly by reinforced stitches placed in each commissure. This procedure may have to be accompanied by cusp extension with fascia lata.

(c) Occasionally regurgitation has been due to lack of support beneath the right coronary/noncoronary commissure, allowing the adjacent margins of the cusps to prolapse. Elevation and fixation of this commissure a few millimetres higher up on the aortic wall may result in competence.

(d) Reconstruction of the whole valve or replacement with a homograft or a mechanical prosthesis will be required in those patients where repair fails to produce competence. In such cases the redundant right coronary cusp can be partially retracted and sutured to the margins of the ventricular defect.

OPERATIVE FINDINGS (Table) The majority of the ventricular septal defects were large, 15 being over $1 \mathrm{~cm} . / \mathrm{m}^{2}$ B.S.A. Seven patients $(26 \%)$ had supracristal defects, an incidence over eight times that in the remainder of our series of surgically corrected ventricular septal defects.
The regurgitation was thought to be due to a $\overrightarrow{\vec{c}}$ prolapsed cusp in 19 patients, a deformed cusp $\vec{\sigma}$ in one, perforated cusps in two (with a partially $\frac{C}{0}$ prolapsed cusp in one), and a sinus of Valsalva $\overline{\frac{\bar{N}}{}}$ aneurysm in three, while in two patients (in whom $\widehat{\nabla}$ aortotomy was not carried out) there was no

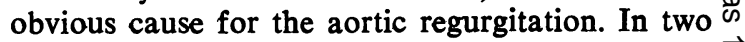
patients a prolapsed or distorted cusp was asso- $\vec{O}$ ciated with a sinus of Valsalva defect, and four $\overrightarrow{ }$ of the five patients with an aneurysm of the sinus $\vec{\omega}$ of Valsalva had fistulae into the right ventricle. $\overrightarrow{\vec{*}}$

The deformed cusp was the right coronary in 19 patients and the non-coronary cusp in one. $A$ Often the portion of the non-coronary cusp $w$ adjacent to the affected right coronary cusp was ON also abnormal. The affected cusp was usually 0 larger than normal, being patulous and thinned out with a long leading edge. There were often $\vec{z}$ areas of thickening in such cusps, either adjacent to the non-coronary cusp or in the most depen- $\vec{\theta}$ dent inferior portion of the prolapsing cusp, and $\mathscr{\odot}$ sometimes small perforations in the thinned out base. The affected cusp was often prolapsing into or through the ventricular septal defect towards the right ventricular outflow tract, thus partially occluding the ventricular septal defect and reducing its effective size. In two patients part of $\mathbb{\unrhd}$ the right coronary cusp and a smaller portion of $\overrightarrow{\vec{B}}$ the adjacent non-coronary cusps were fibrotic 3 and calcified without being obviously prolapsed. In one young child the right coronary cusp was? shortened, thickened, and thus deficient and incompetent.

The majority of the ventricular septal defects $\underset{x}{\stackrel{0}{x}}$ in which there was prolapse of an aortic valve $\dot{\sigma}$ cusp were either supracristal or high infracristal $;$ that is, the defect was sited immediately below the 0 aortic ring, often at the commissure between the right coronary and non-coronary cusp. There was 음 thus an area of aortic ring unsupported by septum, $\supset$ predisposing towards prolapse of the aortic annulus, cusp or sinus.

Three patients had infundibular right ventri- ${ }^{\circ}$ cular hypertrophy requiring resection. One patient $\tilde{O}$ had an associated atrial septal defect which was $N$ closed, and discrete subvalvar aortic stenosiso which was resected. The aortic regurgitation in this patient (case 24) appeared to be due to cusp $\frac{D}{\varnothing}$ perforations. The right coronary cusp was not? prolapsed at surgery but appeared large and lax. 0 The angiographic findings suggested that when the heart was beating the cusp was blown out and ${ }_{\odot}^{\mathbb{D}}$ prolapsing through the defect.

The affected cusp was repaired or hitched upo in 12 patients (Fig. 9), a Starr-Edwards prosthesis was inserted in one patient, a homograft in a 


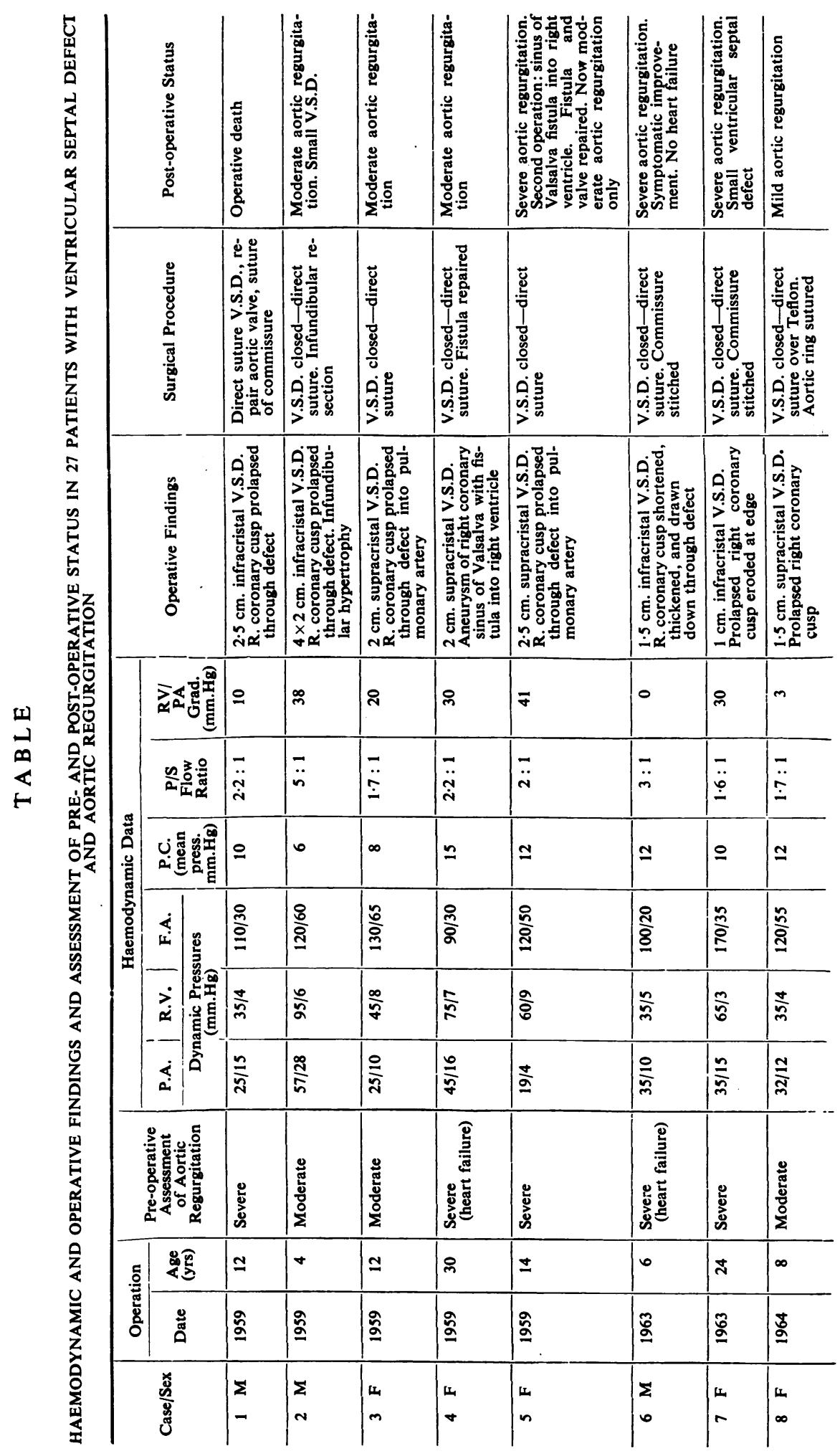

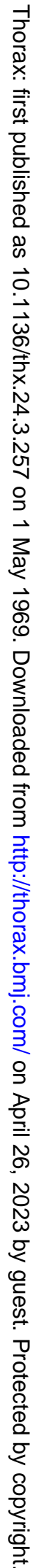




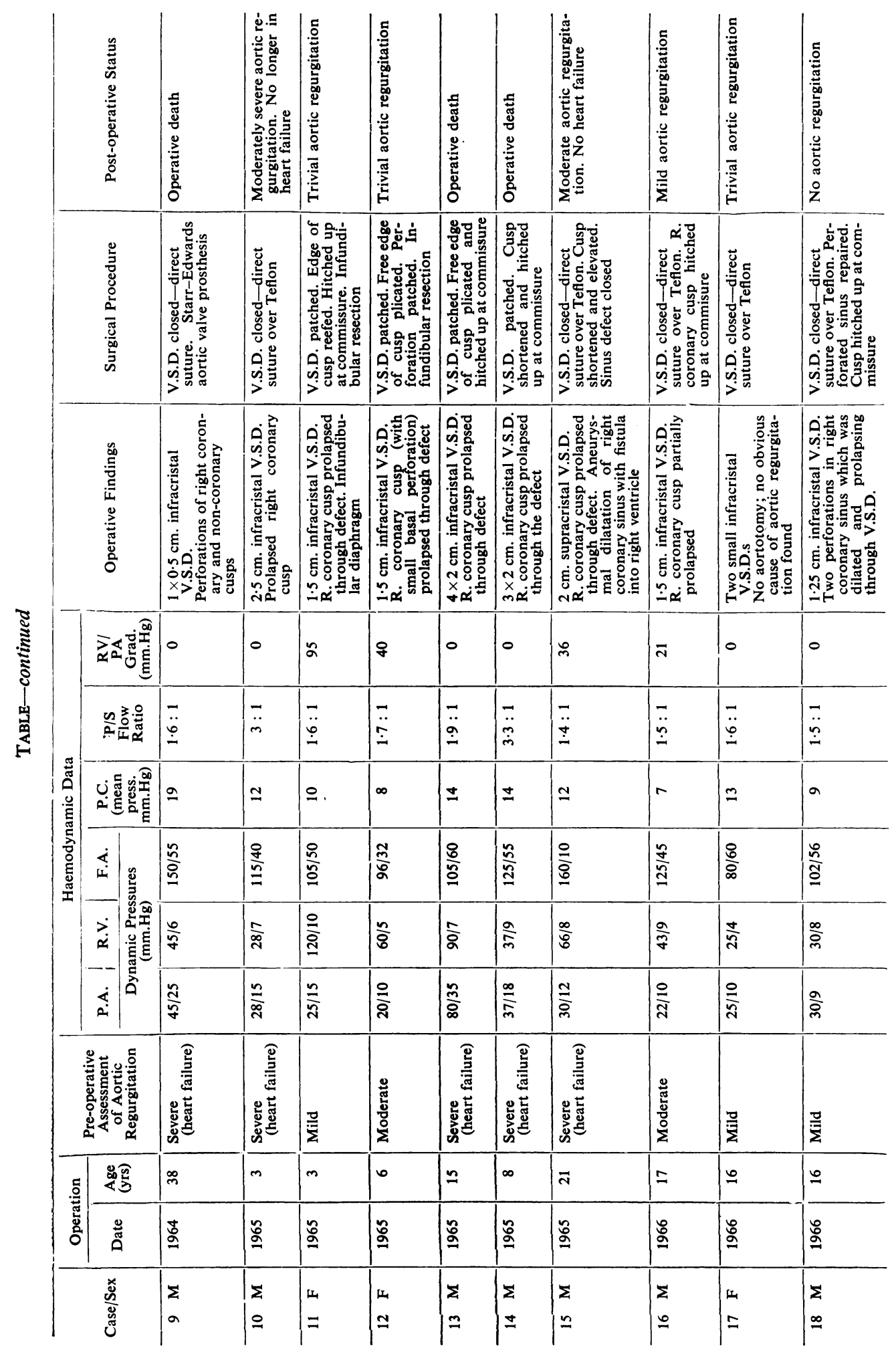

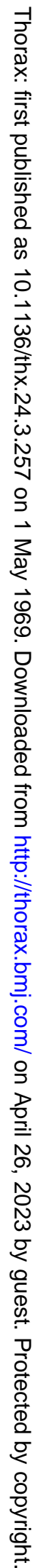




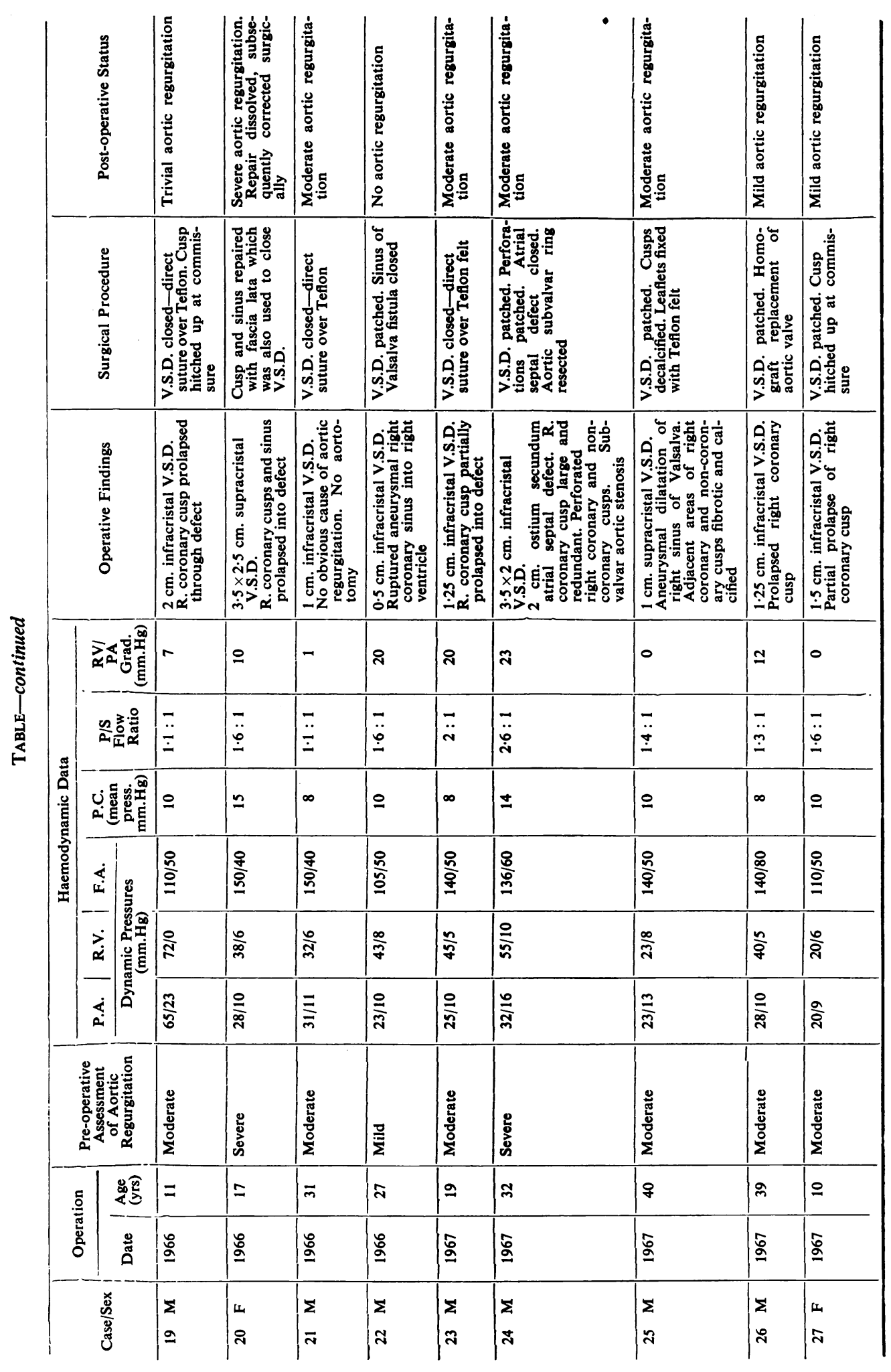

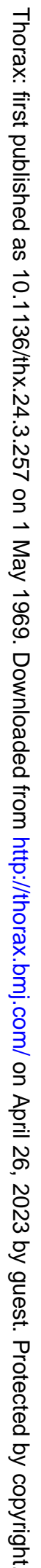



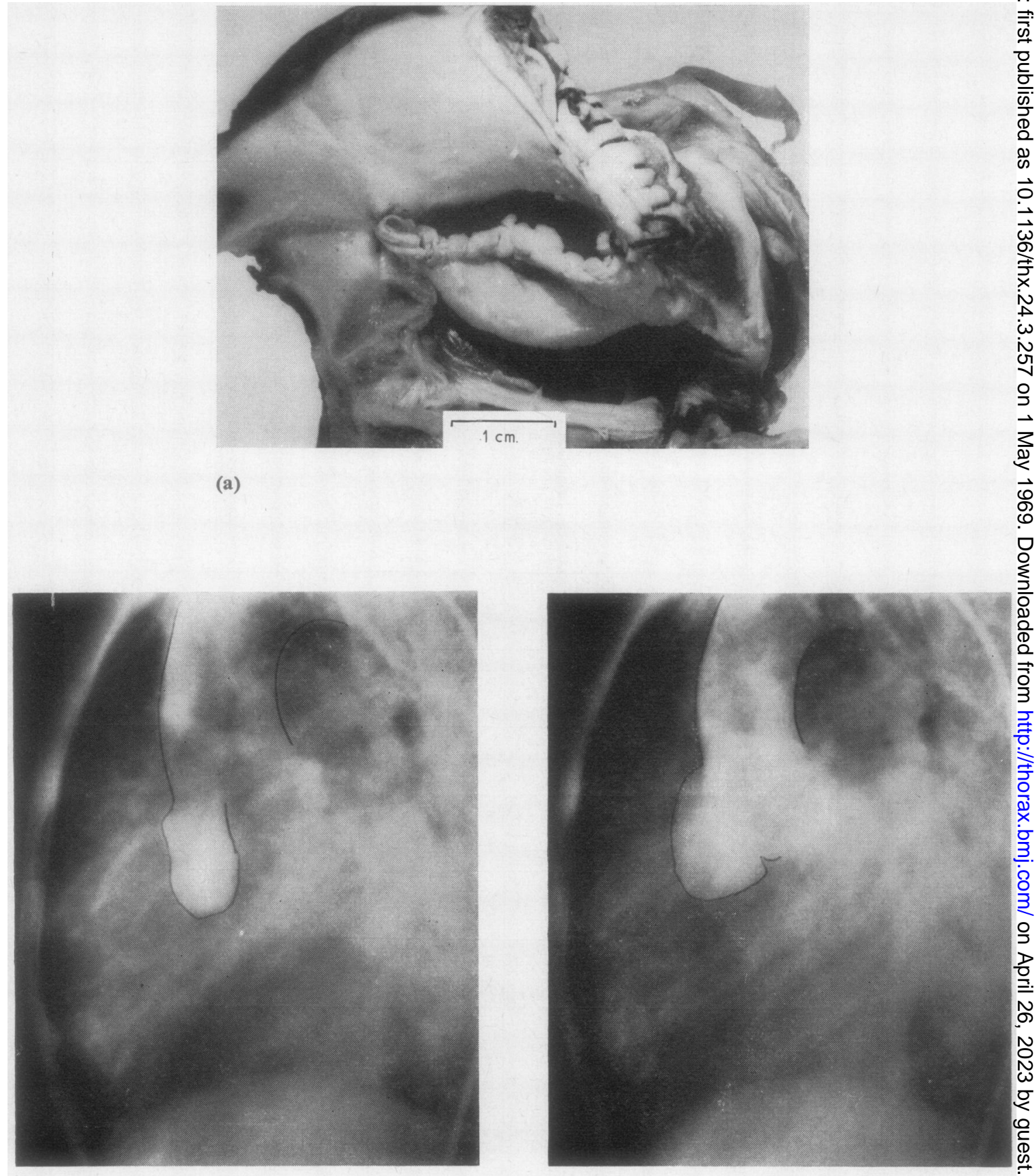

(b)

(c)

FIG. 9. (a) Heart of a 15-year.old boy opened from the left ventricular aspect, showing grossly thickened and $\stackrel{\oplus}{\stackrel{\oplus}{+}}$ redundant right coronary cusp and sinus (the leading edge has been reefed and the commissures stitched) $\mathbb{\Phi}^{+}$ prolapsing into a $4 \times 2.5 \mathrm{~cm}$. infracristal ventricular septal defect. Lateral aortograms of the same patient (b) in systole and $(c)$ in diastole. 
second, and a fascia lata repair was carried out in a third. In eight patients no attempt was made to deal with the aortic regurgitation. The sinus of Valsalva fistulae were closed, and the ventricular septal defects were closed by direct suture or with a patch.

RESULTS OF SURGERY Four patients (17\%) did not survive operation, but three of these patients were in heart failure, and the fourth, with severe aortic regurgitation, was operated on very early in the series. Of the 23 survivors, the residual aortic regurgitation was thought to be severe in 4, moderate in 9 , slight or trivial in 7 , and absent in 3 . The most effective repairs were made in those patients in whom the aortic regurgitation was not severe and who have been operated on more recently. Closure of the ventricular septal defect alone appeared sufficient to halt the progression of the aortic regurgitation and to relieve heart failure in a child of 3 years.

POST-MORTEM FINDINGS Two hearts were available for pathological examination. The first (Fig. 9a) was from a 15-year-old boy, who was in heart failure at the time of operation. His heart weighed $920 \mathrm{~g}$. with dilatation and hypertrophy of all chambers.

There was an infracristal defect, $3 \times 2 \mathrm{~mm}$. in size, situated immediately below the aortic ring, centred between the right coronary and noncoronary cusps. The right coronary cusp was unsupported and prolapsing through the defect. It was very lax and redundant, measuring $32 \mathrm{~mm}$. along its leading edge with a depth of $20 \mathrm{~mm}$. The most dependent part of the cusp was particularly thickened. The adjacent sinus was also dilated and incorporated into the cusp. The noncoronary cusp was also deformed, measuring $22 \times$ $14 \mathrm{~mm}$. The right ventricular outflow tract appeared normal.

Histology of the right coronary cusp showed gross thickening by hyalinized collagen.

The leading edge of the right coronary cusp had been shortened by reefing and the cusp hitched up by stitching the commissure between the right coronary and non-coronary cusps.

The second patient (Fig. 10), an 8-year-old boy, was also in heart failure at the time of operation. The anatomy was similar to that described above, but the affected cusps were not so grossly deformed. It can be seen how the right coronary cusp has been hitched up and the adjoining commissure stitched at the base, using a Teflon pledget. The ventricular septal defect was patched with Teflon.

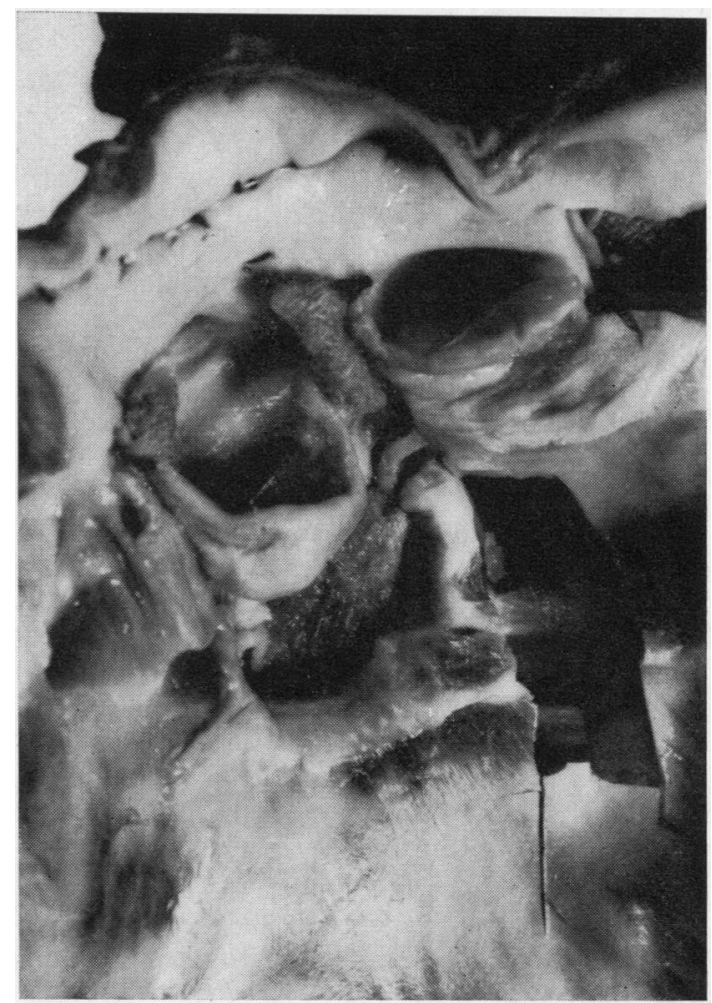

FIG. 10. Heart of an 8-year-old boy opened from the left ventricular aspect to show a $2 \times 1.5 \mathrm{~cm}$. infracristal ventricular septal defect, which has been patched, and a thickened right coronary cusp hitched up at the commissures over Teflon pledgets. ( $A$ block has been taksn for histology.)

MEDICAL PROGNOSIS Even though not all our patients were under continuous medical supervision, certain salient features emerge. Thus, the majority of patients apparently slowly developed progressive aortic regurgitation with increasing left ventricular hypertrophy and eventual development of left ventricular failure.

In three of our patients, in whom the onset of aortic regurgitation was well documented, its progression was extremely rapid, heart failure supervening in less than a year. Six patients were in heart failure at the time of operation.

In one patient, assessed now over a period of 12 years, there appears to have been no obvious increase in aortic regurgitation or heart size.

As previously mentioned, patients with this combination of defects appeared particularly prone to develop infective endocarditis, and this further prejudiced their prognosis. 


\section{DISCUSSION}

PATHOLOGICAL ANATOMY The ventricular septal defect has been classified by Edwards (1960) as follows :

1. Defects related to the ventricular outflow tracts

2. Defects related to the ventricular inflow tracts

3. Defects common to both outflow and inflow tracts

4. Left ventricular-right atrial communication. The defects related to the ventricular outflow tracts have been further subdivided into those situated postero-inferiorly to the crista supra ventricularis and those lying antero-superior to this anatomical landmark. The last mentioned is the less common variety. Becu, Fontana, DuShane, Kirklin, Burchell, and Edwards (1956) found that of 50 hearts with ventricular septal defect 40 showed the defect in the outflow portion of the ventricular septum. In 35 of these the defect lay postero-inferiorly to the crista, while only in four was the defect antero-superior.

The ventricular septal defects associated with aortic regurgitation are situated between the right and non-coronary cusps. The anatomical relations have been described by Nadas, Thilenius, LaFarge, and Hauck (1964). Seven of his cases came to necropsy and were divided into two groups. The first group consisted of four hearts, and then the defect involved the membranous portion of the septum mainly, but also a small portion of the bulbar musculature. Inferiorly, the defect was bounded by a ridge of the main ventricular muscular septum, and superiorly by the commissure between the right and non-coronary (posterior) aortic valve cusps. Both the hearts in our series which were available for post-mortem examination fit the description of Nadas' group 1. The remaining hearts fit into group 2 , and the ventricular septal defect was situated just below the commissure between the right and noncoronary aortic cusps involving the anterior half of the membranous septum and also a portion of the anterior bulbar muscular septum.

The anatomy of the root of the aorta has been described by Edwards and Burchell (1957). Each aortic sinus is subdivided into three more or less equal parts and inferiorly, all parts of the right aortic sinus lying in close relation to the ventricular septum. The muscular portion is constant beneath the central and the left parts, but beneath the posterior part of the right aortic sinus either muscular or membranous portions of the ventri- cular septum may be present. The right part of the posterior aortic sinus is related inferiorly either to the muscular or membranous portions of the interventricular septum.

Over-riding of the aorta is usually present, and was estimated by Nadas et al. (1964) to be about $30 \%$. The aorta is not in contact with the ventricular septal defect at the site of the defect (Ellis, Ongley, and Kirklin, 1963). Slight hypertrophy of the crista supra ventricularis was present in our two necropsied cases, but this can be variable and need not necessarily be present.

The site of the ventricular septal defect is important, and experimental high ventricular septal defects in newborn chicks demonstrated prolapse of the right coronary cusps (de la Cruz, cited by Nadas et al., 1964). The close relationship between the right ventricular outflow tract and the ventricular septum is well described by Edwards and Burchell (1957). The cause of the prolapse of the aortic cusp and its occurrence in some high ventricular septal defects but not in others, even though the anatomical position may be similar, is unknown.

The anatomy and embryology of septal defects in the membranous and bulbar areas of the anterior bulbar septum have been described by Grant, Downey, and MacMahon (1961). By careful dissection they were able to show the normal anatomy of the bulbar muscle. This consisted of two muscular layers: the superficial layer is made up of three components-the one deep layer which originates from the membranous septum and also from the aortico-pulmonary tendon. This tendon is a fibrous ring at the root of the aorta which partly arises from the membranous septum and from the right trigone of the left ventricle. It meets a similar fibrous ring at the root of the pulmonary artery and is inserted in the left trigone. In the light of the above description the defects were subdivided as follows:

(1) defects of the atrioventricular ring; defects in the main body; (3) bulbar defects.

The particular location of bulbar septal defects is governed by the missing superficial bulbar muscle components, whilst a missing deeper component appears to determine the size of the ventricular septal defect. This last component is sometimes difficult to evaluate because only part of this muscle may be missing. The deep bulbar component is inserted into the aortico-pulmonary tendon at the root of the aorta near the aortic cusps. If this muscle layer is absent (and in the absence of bulbar muscle no left ventricular tissue can grow) the anterior lip of the aorta will have no 
attachment to the left ventricle. This then partly explains why some of the aortic valves may be less supported and also the over-riding of the aorta itself.

In our own case two sections were taken showing the root of the aorta, the prolapsed aortic valve, and the underlying muscular portion of the septum. In each there was some definite muscle beneath the aortic valve and, as has been pointed out, unless careful dissection is carried out evaluation of this is indeed very difficult. Control specimens from a case of tetralogy of Fallot showed no discernible difference histologically.

We have confirmed the observation of Nadas et al. (1964) that the signs of aortic regurgitation complicating those of a ventricular septal defect develop after the first year of life, thus adding weight to the supposition that this is an acquired complication.

We have also confirmed the findings of Keck, Ongley, Kincaid, and Swan (1963), Scott, McGuire, Kaplan, Fowler, Green, Gordon, Shabetai, and Davolos (1958), Nadas et al. (1964), and Plauth, Braunwald, Rockoff, Mason, and Morrow (1965) that the most common cause of the aortic regurgitation is a deformed aortic valve cusp, usually the right coronary, sometimes with partial involvement of the adjacent non-coronary cusp. The affected cusp is deformed in several ways, but most commonly prolapses into or through the ventricular septal defect.

The production of aortic regurgitation in sinus of Valsalva aneurysms has been ascribed by London and London (1961) to progressive dilatation of the sinus with eventual distortion of the relevant valve cusp. It seems likely that this mechanism accounted for or contributed to the aortic regurgitation in our six patients with sinus of Valsalva fistulae or aneurysms.

A characteristic of the ventricular septal defects in which prolapse of an aortic cusp had occurred is their high position immediately under the aortic valve ring, thus leaving an unsupported area where there was no continuity between aorta and ventricular septum, as noted by Ellis et al. (1963). A high incidence of supracristal defects has also been noted by others (Ellis et al., 1963 ; Plauth et al., 1965). These authors also noted the ventricular septal defects to be of small size, a finding which we were unable to confirm. Indeed the majority (17) of our ventricular septal defects with a prolapsed cusp were large.

Infundibular pulmonary stenosis with this association of defects has already been described
(Collins, East, Godfrey, Harris, and Oram, 1958 ; Nellen, Schrire, and Vogelpoel, 1959; Nadas et al., 1964 ; Plauth et al., 1965 ; Carlsson, Hartmann, and Kissane, 1965). We were able to demonstrate this in three patients, but found that an infundibular gradient or gradient within the right ventricular cavity was common. Our impression is that hypertrophy of the crista (Ellis et al., 1963) is uncommon, and that the gradient is usually abolished after repair of the ventricular septal defect and aortic regurgitation. It would seem likely, therefore, that at least some of the gradient can be accounted for by prolapse of the aortic cusp (Nadas et al., 1964) through the defect into the right ventricular outflow tract. Our haemodynamic data demonstrating small left-toright shunts with normal pulmonary artery pressures and a large ventricular septal defect can be explained by prolapse of the cusp or sinus, or sometimes of the unsupported aortic annulus into the defect (Plauth et al., 1965), thereby reducing its effective size. This situation was suspected in some of our patients at angiocardiography and demonstrated clearly at surgery. The finding of a large left-to-right shunt with normal pulmonary artery pressures and a large ventricular septal defect can be explained by the fact that the effective size of the ventricular septal defect is reduced by the prolapsed cusp partially occluding it, while a diastolic as well as a systolic left-to-right shunt is made possible from aorta to right ventricle via the incompetent aortic valve and ventricular septal defect.

If the ventricular septal defect is supracristal, it is easy to visualize how the right or noncoronary cusp, sinus, and even the aortic ring can prolapse downwards into the defect. Figure 11 shows the heart of a 3-year-old boy with a supracristal ventricular septal defect showing how the right coronary cusp is deformed and enlarged, already potentially falling through the defect, though there was no clinical evidence of aortic regurgitation.

The right and non-coronary cusps in an infracristal defect look directly into the ventricular septal defect when it is situated immediately under the aortic ring. It is possible that a jet of blood impinges on the base of the cusp, causing localized thickening. It will then tend to elongate and with each successive cardiac cycle to be drawn down through the open septum, often resulting in elongation of the relevant sinus.

The difficulties of differential diagnosis are shown by Morgan and Burchell (1950), Scott 


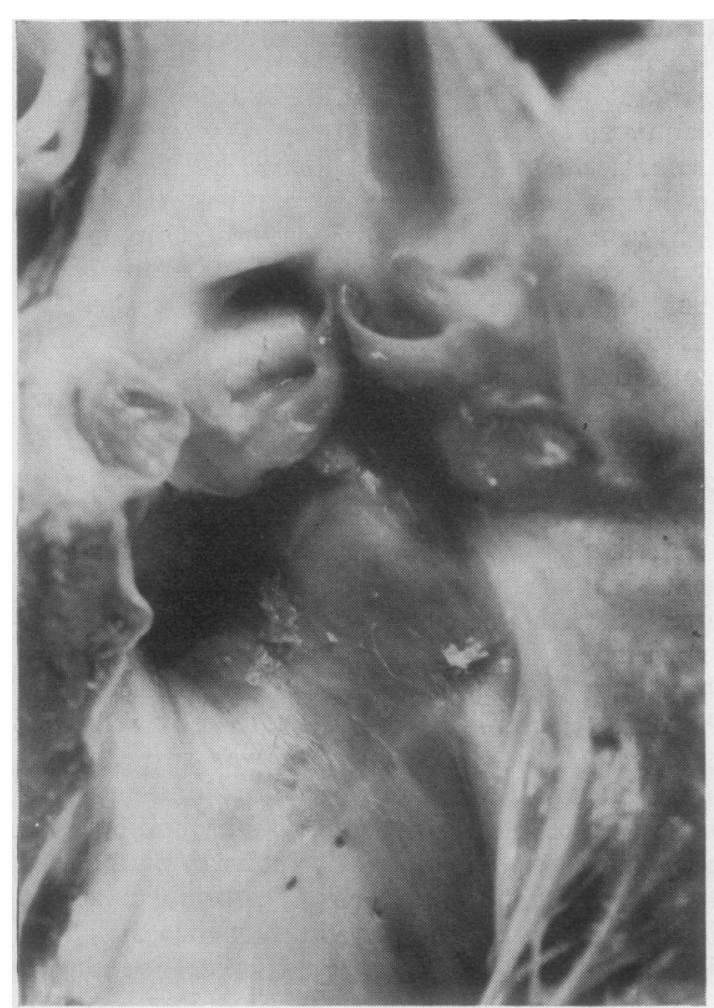

FIG. 11. Heart of a 3-year-old boy opened from the left ventricular aspect to show a supracristal ventricular septal defect and a deformed right coronary cusp overlying the defect.

et al. (1958), Winchell and Bashour (1956), Claypool, Ruth, and Lin (1957), and Denton and Pappas (1958). Gross (1952) noted that an erroneous clinical diagnosis of patent ductus arteriosus had resulted in needless thoracotomies. More recently, increasing awareness of the combination of ventricular septal defect and aortic regurgitation has made us more appreciative of clues in its diagnosis. Patent ductus arteriosus can be excluded clinically, mainly by the site of intensity of the murmurs which are maximal at the lower left sternal edge and the disproportionate left ventricular enlargement both clinically and radiologically.

We have noted a high incidence of infective endocarditis in our patients as compared with the low incidence in isolated ventricular septal defects (Shah, Singh, Rose, and Keith, 1966), and we con- firmed the findings of Nadas et al. (1964) that the infection often occurs after the development of aortic regurgitation. It was not confined to those who had severe aortic regurgitation. Possibly the jet lesion from the ventricular septal defect renders the prolapsed cusp of the aortic valve more vulnerable to infection.

We have also confirmed in general the progressive nature of the aortic regurgitation in our patients (Nadas et al., 1964 ; Plauth et al., 1965) with slow or rapid progression to left ventricular failure. The course of an individual patient appeared to be unpredictable, however.

Recent surgical procedures have given encouraging results, and with the known poor medical prognosis and high incidence of infection, we now feel that surgery should be offered to these patients on first diagnosis.

We are most grateful to Professor R. E. Steiner for radiological advice and co-operation, and to Professor H. H. Bentall for kindly allowing us to quote his surgical results and for advice. Mr. Gerald Rainbow supervised the technical aspects of the haemodynamic studies, and we are indebted to him for his expert assistance.

\section{REFERENCES}

Becu, L. M., Fontana, R. S., DuShane, J. W., Kirklin, J. W., Burchell, H. B., and Edwards, J. E. (1956). Anatomic and pathologic studies in ventricular septal defect. Circulation, 14, 349.

Carlsson, E., Hartmann, A. F. Jr., and Kissane, J. M. (1965). Ventricular septal defect with prolapsed aortic valve and outflow tract obstruction. Acta Radiol. (Diagn.), 3, 554.

Claypool, J. G., Ruth, W., and Lin, T. K. (1957). Ventricular septal defect with aortic incompetence simulating patent ductus arteriosus. Amer. Heart J., 54, 788.

Collins, D. M., East, T., Godfrey, M. P., Harris, P., and Oram, S (1958). Ventricular septal defect with pulmonary stenosis and aortic regurgitation. Brit. Heart J., 20, 363.

de la Cruz, M. V. (1964). (Cited by Nadas, A. S., et al., 1964, personal communication.) Vide infra.

Denton, C., and Pappas, E. G. (1958). Ventricular septal defect and aortic insufficiency: report of three cases. Amer. J. Cardiol., 2, 554.

Edwards, J. E. (1960). In Pathology of the Heart. Ed. Gould, S. E Charles C. Thomas, Springfield, Illinois.

and Burchell, H. B. (1957). The pathological anatomy of deficiencies between the aortic root and the heart, including aortic sinus aneurysms. Thorax, 12, 125.

Ellis, F. H., Ongley, P. A., and Kirklin, J. W. (1963). Ventricular septal defect with aortic valvular incompetence. Surgical considerations. Circulation, $27,789$.

Grant, R. P., Downey, F. M., and MacMahon, H. (1961). The architecture of the right ventricular outflow tract in the normal human heart and in the presence of ventricular septal defects. human heart
Ibid., 24, 223.

Gross, R. E. (1952). The patent ductus arteriosus. Observations on diagnosis and therapy in 525 surgically treated cases. Amer. J. Med., 12, 472 .

Keck, E. W. O., Ongley, P. A. Kincaid, O. W., and Swan, H. J. C. (1963). Ventricular septal defect with aortic insufficiency. A clinical and hemodynamic study of 18 proved cases. Circulation, 27, 203.

London, S. B., and London, R. E. (1961). Production of aortic regurgitation by unperforated aneurysm of the sinus of Valsalva. Ibid., 24, 1403 
Laubry, C., and Pezzi, C. (1921). Traité des Maladies Congénitales du Cour. Baillière, Paris.

Morgan, E. H., and Burchell, H. B. (1950). Symposium on cardiac catheterization; ventricular septal defect simulating patent ductus arteriosus. Proc. Mayo Clin., 25, 69.

Nadas, A. S., Thilenius, O. G., LaFarge, C. G., and Hauck, A. J. (1964). Ventricular septal defect with aortic regurgitation. Medical and pathologic aspects. Circulation, 29, 862.

Nellen, M., Schrire, V., and Vogelpoel, L. (1959). Ventricular septal defect with aortic incompetence. S. Afr. med. J., 33, 91.

Plauth, W. H., Jr., Braunwald, E., Rockoff, S. D., Mason, D. T., and Morrow, A.' G. (1965). Ventricular septal defect and aortic regurgitation. Clinical, hemodynamic and surgical considerations. Amer. J. Med., 39, 552.

Scott, R. C., McGuire, J., Kaplan, S., Fowler, N. O., Green, R. S. Gordon, L. Z., Shabetai, R., and Davolos, D. D. (1958). The syndrome of ventricular septal defect with aortic insufficiency. Amer. J. Cardiol., 2, 530.

Seldinger, S. I. (1953). Catheter replacement of the needle in percutaneous arteriography; a new technique. Acta Radiol. (Stockh.) $39,368$.

Shah, P., Singh, W. S. A., Rose, V., and Keith, J. D. (1966). Incidence of bacterial endocarditis in ventricular septal defects. Circulation, 34, 127.

Winchell, P., and Bashour, F. (1956). Ventricular septal defect with aortic incompetence simulating patent ductus arteriosus. Amer. J. Med., 20,361.

\section{ADDENDUM}

Longar follow-up of patients who have had repair procedures has shown that aortic regurgitation may reappear or progress. However, we regard the treatment as surgical, while realizing that the ideal operative procedure has not yet been devised. Homograft replacement, the most appealing procedure, may be impossible in children because of the small aortic valve ring; similarly, a prosthesis may be impractical and is undesirable in this age group. We would then regard a repair procedure as being indicated initially in a child with more than slight aortic regurgitation, envisaging homograft replacement as a definitive procedure where necessary. 